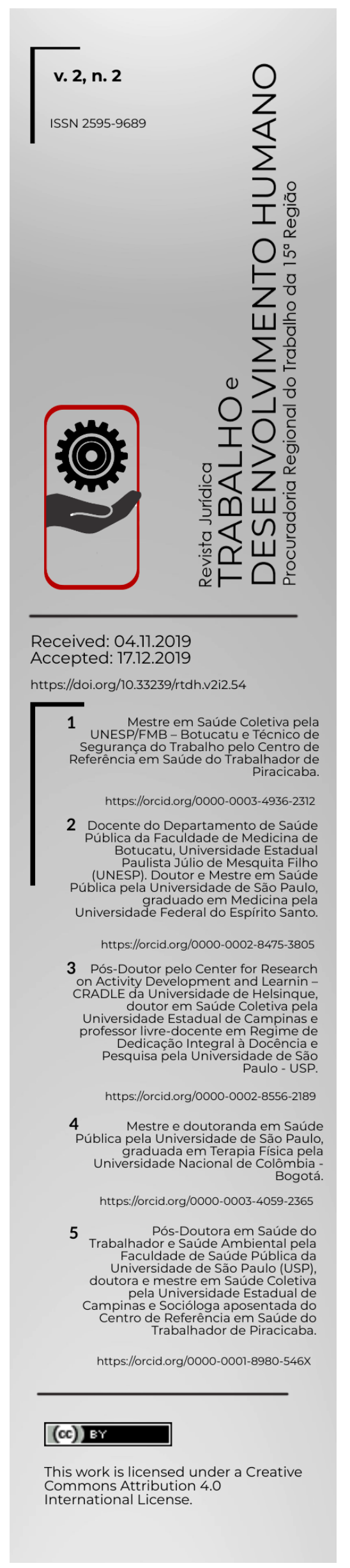

\title{
Acidentes incubados na regulação do setor elétrico: estudo de determinantes organizacionais e de suas consequências sociais
}

\author{
incubated accidents in the regulation of the electricity sector: study of \\ organizational determinants and their social consequences \\ accidentes incubados en la regulación del sector eléctrico: estudio de los \\ determinantes organizativos y sus consecuencias sociales
}

\author{
Alessandro José Nunes Silva ${ }^{1}$ \\ Ildeberto Muniz de Almeida² \\ Rodolfo Andrade de Gouveia Vilela ${ }^{3}$ \\ Sandra Lorena Beltran Hurtado 4 \\ Mara Alice Conti Takahashi ${ }^{5}$
}

\section{RESUMO}

Desde sua privatização, mudanças organizacionais no setor elétrico brasileiro impactam a saúde e segurança dos trabalhadores. Este estudo é motivado por quatro objetivos: descrever (1) desfechos imediatos e tardios de um acidente de trabalho grave no setor elétrico; (2) aspectos técnicos e proximais do acidente e; 3 ) origens organizacionais e gerenciais incubadas na história do sistema, (4) descrever em profundidade os determinantes organizacionais que contribuíram na ocorrência do acidente. Neste estudo de caso realizou-se análise documental, entrevistas, grupo focal, e observação direta. Os acidentes têm efeitos diretos e indiretos aos trabalhadores e familiares: dificuldades na reintegração familiar, no meio social e nas relações de trabalho. 0 estudo de caso permite elaborar hipóteses que sugerem avaliações para verificar se os achados estão se repetindo no setor. $O$ caso revela que as decisões gerenciais no nível local se associam a aspectos da regulação pública que tem como objetivos: (a) a redução do tempo de interrupção de energia, e (b) a redução do preço das tarifas. Estes dois parâmetros têm implicação na acidentalidade do setor, introduzindo fatores organizacionais patogênicos no sistema, seja na introdução de pressão de tempo para a realização de tarefas perigosas, seja na realização de cortes em investimentos, na manutenção, na contratação de pessoal especialmente via terceirização e precarização da força de trabalho, no treinamento e na segurança. A análise em profundidade de acidentes pode contribuir para elucidar como determinantes organizacionais introduzem distúrbios no sistema facilitando os acidentes. Transformar e intervir sobre esses determinantes pode contribuir para tornar o trabalho mais seguro e sustentável.

PALAVRAS-CHAVE: Acidentes de trabalho; Análise de acidente; Prevenção de acidentes; Terceirização; Distribuição de energia elétrica

\section{ABSTRACT}

Since its privatization, organizational changes in the Brazilian electricity sector have impacted the health and safety of workers. This study is motivated by four objectives: (1) to describe the immediate and later outcomes of a serious occupational accident in the electrical sector; (2) technical and proximal aspects of the accident; and (3) organizational and managerial origins incubated in the history of the system, (4) to describe in depth the organizational determinants that contributed to the occurrence of the accident. In this case study, documentary analysis, interviews, focus group, and direct observation were performed. Accidents have direct and indirect effects on workers and their families: difficulties in family reintegration, in the social environment and in work relations. The case study allows the development of hypotheses that suggest evaluations to verify if the findings are being repeated in the sector. The case shows that management decisions at the local level are associated with aspects of public regulation that have as objectives: (a) the reduction of the energy interruption time, and (b) the reduction of the price of tariffs. These two parameters have implications on the accidentality of the sector, introducing pathogenic organizational factors in the system, whether in the introduction of time pressure to perform dangerous tasks, or in making cuts in investments, in maintenance, in hiring personnel, especially via outsourcing and precariousness of the workforce, in training and in safety. In-depth analysis of accidents can help to clarify how organizational determinants 
introduce disturbances into the system by facilitating accidents. Transforming and intervening on these determinants can contribute to making work safer and more sustainable.

KEYWORDS: Occupational accidents; Accident analysis; Accident prevention; Outsourcing; Electricity distribution.

\section{RESUMEN}

Desde su privatización, los cambios organizativos en el sector eléctrico brasileño han afectado la salud y la seguridad de los trabajadores. Este estudio está motivado por cuatro objetivos: (1) describir los resultados inmediatos y tardíos de un accidente laboral grave en el sector eléctrico; (2) los aspectos técnicos y proximales del accidente; y (3) los orígenes organizacionales y gerenciales incubados en la historia del sistema; (4) describir en profundidad los determinantes organizacionales que contribuyeron a la ocurrencia del accidente. En este estudio de caso, se realizaron análisis documentales, entrevistas, grupos focales y observación directa. Los accidentes tienen efectos directos e indirectos sobre los trabajadores y sus familias: dificultades en la reintegración familiar, en el entorno social y en las relaciones laborales. El estudio de caso permite el desarrollo de hipótesis que sugieren evaluaciones para verificar si los hallazgos se están repitiendo en el sector. El caso muestra que las decisiones de gestión a nivel local están asociadas a aspectos de la regulación pública que tienen como objetivos: a) la reducción del tiempo de interrupción de la energía, y b) la reducción del precio de las tarifas. Estos dos parámetros tienen implicaciones sobre la accidentalidad del sector, introduciendo factores organizativos patógenos en el sistema, ya sea en la introducción de la presión del tiempo para realizar tareas peligrosas, o en la reducción de inversiones, en el mantenimiento, en la contratación de personal, especialmente a través de la externalización y la precariedad de la mano de obra, en la formación y en la seguridad. Un análisis en profundidad de los accidentes puede ayudar a aclarar cómo los determinantes de la organización introducen perturbaciones en el sistema al facilitar los accidentes. La transformación y la intervención en estos determinantes pueden contribuir a hacer que el trabajo sea más seguro y sostenible.

PALABRAS CLAVE: Accidentes de trabajo; Análisis de accidentes; Prevención de accidentes; Outsourcing; Distribución de energía eléctrica.

\section{INTRODUÇÃO}

O predomínio hegemônico do ideário neoliberal e a globalização financeira da economia, com internacionalização de bens e serviços que desrespeita as fronteiras do Estado-Nação, impuseram processo de racionalização e intensificação do trabalho humano (DRUCK; FRANCO; BORGES, 2007). Os grandes conglomerados econômicos atuam em rede objetivando usufruir vantagens competitivas de diferentes países, com ênfase na contratação de mão de obra barata e sem as "amarras" da legislação estatal de regulação das condições de trabalho e de proteção social. O aumento da competição têm sido um dispositivo de gestão amplamente utilizado para redução dos custos da força de trabalho (DRUCK; FRANCO; BORGES, 2007).

Na mesma lógica, os serviços estatais essenciais foram significativamente atingidos saúde, educação, previdência social, transportes, energia elétrica - resultando em 
privatizações e consequente ressignificação do papel do Estado e de suas atividades antes exclusivas (DRUCK, 2016).

No âmbito privado, houve profunda reconfiguração das empresas em geral envolvendo processos de reestruturação produtiva e reengenharia de postos de trabalho, e formas de organização que resultaram em desemprego, intensificação e precarização das condições de trabalho (ANTUNES, 2012).

Vários dispositivos de gestão são acionados para obter a intensificação do trabalho: aumento do controle de desempenho, de horas extras e da densidade do trabalho; aumento das metas de produção, das funções e responsabilidades em trabalhos com carga cognitiva; redução da carga horária com efetivo menor; invasão do trabalho no tempo de descanso do trabalhador, limitando ou impedindo a regulação social e familiar (KREIN, 2009).

Estes dispositivos também passaram a ser utilizados no âmbito do Estado, agora reformado e enxuto, cujo papel e responsabilidades foram igualmente transformados: o Estado provedor de serviços essenciais a população passou a ser o Estado regulador, que estabelece condições de operação para serviços autorizados, e o Estado auditor, que avalia os resultados (BALL, 2004).

Os impactos gerais destas mudanças foram estudados, mostrando a consistente relação de causalidade entre os processos de privatização, terceirização, e a precarização das condições e relações de trabalho e seus efeitos adversos para a saúde dos trabalhadores (DIEESE, 2017; MANDARINI; ALVES; STICCA, 2016; MILCH; LAUMANN, 2016; WEIDENBAUM, 2005).

No Brasil, o setor de energia elétrica merece destaque por suas rápidas mudanças, seja nas bases tecnológicas, concebidas exclusivamente para otimização da produção e do barateamento tarifário, seja nas práticas gerenciais, decorrentes da privatização das concessionárias de distribuição. Tais mudanças não foram acompanhadas de políticas públicas e práticas de prevenção e controle de agravos relacionados ao trabalho e introduziram novos perigos à saúde dos trabalhadores (SILVA et al., 2018).

Nos últimos anos a taxa de mortalidade do setor elétrico por acidentes de trabalho foi em média cinco vezes maior do que a dos demais setores formais da economia (Figura 1). A 
maior parte destes acidentes ocorreu na manutenção da rede de distribuição de energia elétrica, privatizada em meados da década de 1990, em fiação de linha aérea convencional (linha viva), energizada e desprotegida (SILVA, 2015).

Figura 1: Taxa de mortalidade (TM) do setor elétrico a cada 100.000 trabalhadores, efetivos, terceiros, força de trabalho geral do setor elétrico e força de trabalho geral do Brasil, de 2004 a 2013, no Brasil.

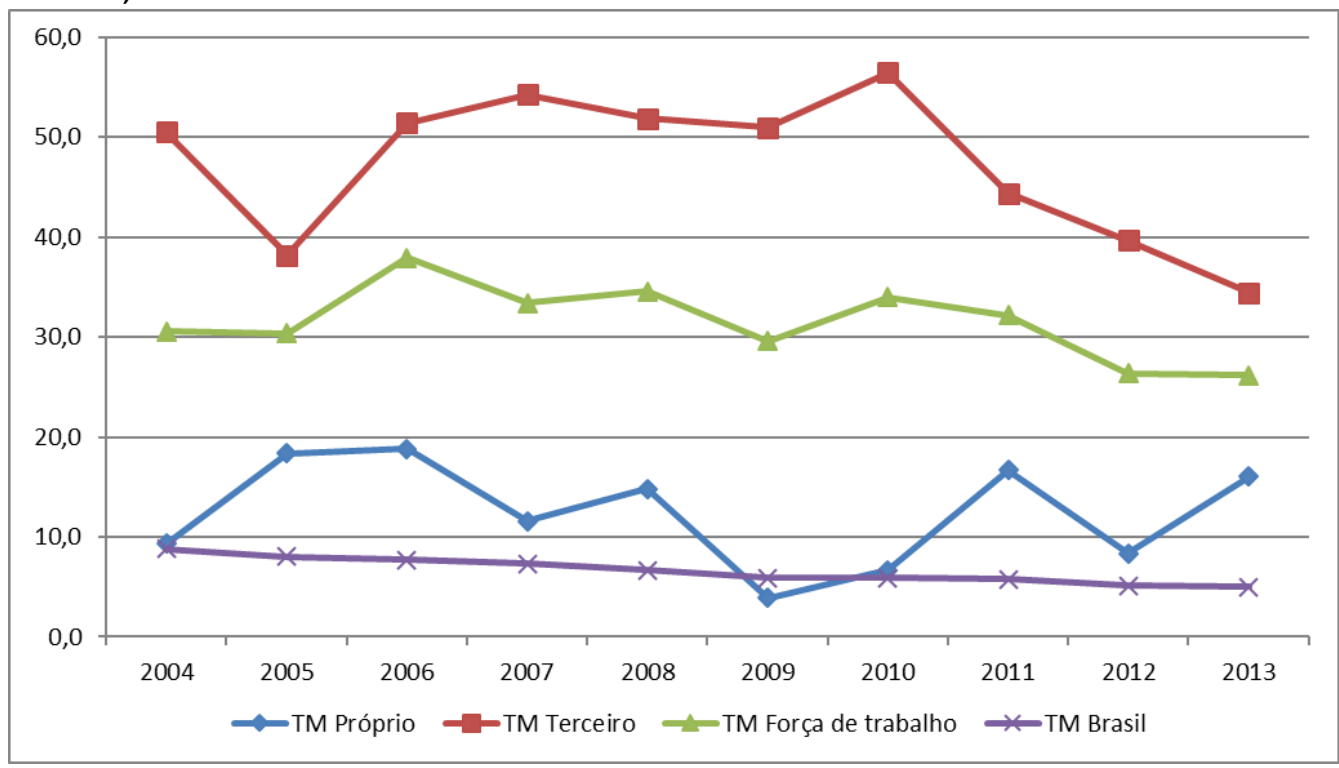

Fonte: SILVA et al., 2018, p. 3.

Este estudo explora um acidente de trabalho do setor elétrico buscando analisá-lo como fenômeno organizacional, com origens e consequências associadas à história do sistema sócio técnico em questão, revelando causas e consequências, proximais e distais ou latentes (HALE et al., 2007).

Em síntese, trata-se de explorar as análises de acidentes apoiadas no enfoque organizacional, no uso de conceitos de diferentes áreas do conhecimento que permitam trazer para a agenda da prevenção processos de escolhas estratégicas adotadas (tecnologias usadas, gestão de produção, manutenção, de pessoal, de comunicações, gestão de mudanças etc.), com ênfase na rede de múltiplas interações decorrentes dessas decisões com as origens de infortúnios e ou para melhorias da gestão de segurança. O reconhecimento da contribuição 
potencial nas origens de acidentes de aspectos como escolhas gerenciais, organizacionais, tecnológicas e outras presentes na história do sistema foi descrito na literatura (Llory, 1999) como processo de incubação desses eventos e, desde então, está associado a crescimento da defesa de sua abordagem em estratégias de prevenção. Em outras palavras, denuncia-se que sua persistência como aspectos intocados embute a possibilidade de contribuições em acidentes futuros. Ou, como também é comum, crescem críticas aos limites de práticas de segurança focadas em origens proximais ou imediatas desses eventos.

No caso em análise, especial interesse foi posto nas decisões gerenciais para alcançar objetivos e metas de produtividade introduzidas pela Agência Nacional de Energia Elétrica ANEEL. Estariam as metas de qualidade e de rebaixamento tarifário, preconizadas pela agência reguladora do setor, paradoxalmente, participando nas origens dos acidentes de trabalho?

A busca por respostas a esta questão permitiu delimitar quatro conjuntos de objetivos para este estudo: (1) Descrever desfechos imediatos e tardios de acidente de trabalho grave no setor elétrico; (2) Descrever aspectos técnicos do acidente propriamente dito e suas origens proximais e; 3 ) Descrever origens organizacionais e gerenciais incubadas na história do sistema; 4) Descrever em profundidade os determinantes organizacionais que contribuíram na ocorrência do acidente.

\section{METODOLOGIA}

Para a construção do caminho teórico de análise deste estudo, utilizou-se dos conceitos descritos no Modelo de Análise e Prevenção de Acidentes de Trabalho (MAPA) Almeida et al, (2014). O primeiro, de Vigilância em Saúde do Trabalhador (VISAT) destaca três dimensões do acidente, a saber: (a) os macro determinantes das escolhas políticas e de regulação dos processos de criação de sistemas sócio técnicos e ambientais - SSTA; (b) a exposição aos perigos e riscos introduzidos com esses novos SSTA e seus respectivos sistemas de gestão de segurança e, (c) as suas consequências ou efeitos. O segundo, o do modelo de gravata-borboleta como representação do fenômeno acidente, com o lado esquerdo explorando tanto as origens proximais como as distais ("causas" em profundidade) dos 
acidentes e o lado direito, a exploração das consequências proximais e distais do ocorrido (HALE et al, 2007). O terceiro, da análise organizacional do evento de Reason, (1997), Llory (1999) e Llory M, Montmayeul, (2014).

O MAPA consiste em realizar: (i) uma descrição e análise do trabalho habitual ou das práticas estabelecidas, considerando as variabilidades mais frequentes e suas origens. Esta análise se baseia essencialmente na abordagem da Ergonomia da Atividade (GUERIN et al., 2004); (ii) associa ainda a análise de mudanças que busca identificar as variabilidades que tiveram participação no evento e seus antecedentes, abordagem apoiada nos conceitos da árvore de causas (BINDER; MONTEAU; ALMEIDA, 1995); (iii) outro pilar é a análise de barreiras sugerida por Hollnagel, (2004 e 2008) que busca entender, a partir da identificação de nocividade potencial existente, quais eram ou deveriam ser as medidas de controle para eliminar ou impedir sua liberação e danos; (iv) finalmente, sugere que a análise seja sempre complementada com o apoio de conceitos de diferentes áreas do conhecimento já aplicadas em estudos de acidentes e que se mostrem úteis no caso em análise. Esta etapa foi denominada ampliação conceitual da análise. Nela destacam-se teorias que abordam 0o acidente normal ou sistêmico de Perrow (1999), a análise organizacional anteriormente mencionada e noções como as de armadilhas cognitivas, erros de modo, intrusão do habitual, entre outras. A exploração de origens de comportamentos com esse aporte conceitual está em consonância a ideia de incubação de acidentes, em especial no que se refere a contribuições de aspectos da concepção e inovações de e em sistemas sócio técnicos. Além disso esses aportes ajudam a construir explicações sobre a dimensão humana nesses eventos que rompem com a ideia de que as ações humanas sejam sempre escolhas intencionais, racionais e livres de constrangimentos num mundo de trabalho previamente conhecido e imutável.

Estes aspectos investigados não costumam aparecer nas análises retrospectivas realizadas devido, tanto à condição marginal de poder em que é posta a gestão de segurança, quanto à carência de ferramentas conceituais e técnicas assim como, à falta de condições políticas que permitam sua utilização em análises conduzidas por agentes externos. 
Neste estudo esse aspecto foi superado graças ao acesso privilegiado a atores-chaves que detinham vivência prática acumulada no setor, onde permitiram entrevistas individuais com duração de seis horas com quatro eletricistas/sindicalistas com vivência histórica no processo de privatização de sua empresa/concessionária de energia elétrica e entrevista individual com duração de quatro horas com um pesquisador e economista do Departamento Intersindical de Estatística e Estudos Socioeconômicos - DIEESE, com vivência como assessor do movimento sindical e participação em reuniões técnicas com a ANEEL (POUPART, 2012).

Além disso também foram coletadas em quatro horas informações por meio de um grupo focal, com cinco sindicalistas do Estado de Minas Gerais, escolhidos pela participação na atualização da Norma Regulamentadora № 10 que trata da segurança em instalações e serviços de eletricidade (BRASIL, 2016). Estas características dos entrevistados contemplam um dos aspectos mais valorizados pela pesquisa qualitativa (HAMMERSLEY, 1992 apud POUPART, et al., 2012, p. 114).

Foi realizada pesquisa documental (Comunicação de Acidente de Trabalho, Procedimentos de Trabalho, Boletim de Ocorrência, Investigação de acidente da equipe de segurança e da CIPA) em Inquérito Civil sobre acidentes do setor elétrico, no Ministério Público do Trabalho de uma região paulista, relatórios técnicos do DIEESE (2010), dados da Fundação COGE, legislação da ANEEL e literatura científica sobre a temática.

O estudo abrangeu também observação direta de atividades de trabalhadores do quadro próprio e terceirizados por um período de 22 horas, na instalação e manutenção da rede de distribuição elétrica, tais como trocas de cruzetas, trocas de para-raios, trocas de linha secundária, entre outras, com registros fotográficos e vídeos dos diálogos informais ocorridos durante as observações de campo. Algumas destas verbalizações estão na produção cinematográfica de dois documentários: Dublê de eletricista (MAIA e MACHADO, 2015; e Eletricitários (NOVAES e SILVA, 2016).

As entrevistas individuais e em grupo, como também os diálogos informais, foram gravados, transcritos e posteriormente selecionadas e agrupadas em categorias analíticas, previamente determinadas - privatização, terceirização, manutenção e investimentos em 
infraestrutura e gestão da segurança. O anonimato dos entrevistados foi garantido pela identificação pela letra $E$ e, para os participantes do Grupo Focal, pelas letras GF.

Este artigo é parte dos resultados da dissertação de mestrado de um dos autores, integrante do projeto temático (Processo no 2012-04721-1), aprovado pelo Comitê de Ética da Faculdade de Saúde Pública, Universidade de São Paulo (CAAE 11886113.5.0000.5421).

\section{CONTEXTUALIZAÇÃO DOS INDICADORES DE DESEMPENHO NO SETOR DE DISTRIBUIÇÃO ELÉTRICA}

Na década de 1960, o governo brasileiro assumiu o setor elétrico, que era exíguo e de baixa confiabilidade, ampliando-o e modernizando-o. Na década de 1980, o setor estatal alçou a categoria internacional de um dos mais extensos e avançados sistemas de distribuição de energia elétrica, tornando-se exportador desse aparato para outros países da América Latina. Indicadores DEC (Duração em horas equivalente de interrupção por consumidor do conjunto considerado) e FEC (Frequência equivalente de interrupção por consumidor do conjunto considerado) de confiabilidade alcançaram níveis de interrupções dos mais baixos do mundo (CASTRO e OLIVEIRA, 2001).

No final dos anos 1990, houve nova e significativa mudança organizacional, com a transferência, via processo de leilão, das concessionárias estatais para a iniciativa privada.

A privatização traz em si o ideário da livre concorrência de mercado e do controle exercido pelo Estado de cunho neoliberal, através da ANEEL, por meio de duas modalidades a regulação de preço da tarifa e a regulação por incentivos a diminuir custos. Para tanto, a agência de regulação estabeleceu sistema de avaliação do desempenho das empresas, oferecendo incentivos para redução de custos e inovações tecnológicas, de forma a aumentar a produtividade (DIEESE, 2014). Com base nos indicadores DEC e FEC, a agência criou o Indicador de Desempenho Global de Continuidade, de modo a comparar anualmente os desempenhos das empresas distribuidoras de eletricidade do país (ANEEL, 2010). Quando o desempenho da concessionária atende o indicador global, ela recebe incentivo financeiro de 
$1 \%$ do faturamento anual, caso contrário, a empresa pode perder, no ano seguinte, $1 \%$ de sua receita.

\title{
3 GESTÃO PELA TERCEIRIZAÇÃO E LÓGICA FINANCEIRA SUSTENTADA NO CURTÍSSIMO PRAZO
}

Na perspectiva de redução de custos, a privatização foi fortemente marcada por redução drástica de pessoal, afetando a capacidade técnica das empresas em leilão, conforme relato de representante sindical:

\begin{abstract}
Para tornar as empresas mais atrativas ao mercado, em 1997, o governo FHC lançou programa intensificado de demissão voluntária, com grandes remunerações. Saiu muita gente ao mesmo tempo da empresa, trazendo perdas a sua parte técnica muito rapidamente (...) ao mesmo tempo que começou processo agressivo e crescente de terceirização. Nós éramos algo próximo de 20.000 trabalhadores na nossa base, em 1997. E chegamos a 7.000 trabalhadores em 2013 e 2014 (E1).
\end{abstract}

Em dados gerais, o DIEESE (2010) mostrou que, em 1994, o setor elétrico brasileiro contava com 183.380 trabalhadores efetivos das empresas concessionárias de gestão pública e, após a privatização em 2005, esse contingente foi reduzido para 94.398. Considerando a taxa de crescimento do setor, o aumento da demanda de trabalho e suas especificidades técnicas, foi possível supor que a diferença tenha sido compensada pela contratação de trabalhadores terceirizados. A inserção dos mesmos foi acompanhada de expressivo aumento da acidentalidade (figura 1).

O caso selecionado para este estudo vitimou trabalhador de empresa contratada e envolve outras circunstâncias relacionadas às mudanças pós privatização.

\section{AS MORTES NO TRABALHO E DECISÕES GERENCIAIS}

De um modo geral, no período de 2003 a 2013, a taxa de mortalidade no setor elétrico, foi, em média, 4,9 vezes maior que a dos demais setores formais da economia, substancialmente elevada para o segmento dos trabalhadores terceirizados, e com variação 
de 4,7 a 18,9 vezes maior que a taxa de mortalidade referente aos trabalhadores efetivos (SILVA et al., 2018).

Estes dados foram evidenciados tanto em estudo do DIEESE (2010) que concluiu que existe maior risco de morte no segmento terceirizado do setor elétrico no Brasil, quanto em estudo comparativo de Gomes da Silva (2013) entre acidentes de trabalho fatais no setor elétrico brasileiro e de outros países, inferindo como causa principal o aumento da contratação de empresas terceirizadas.

Sindicalistas apontam para a terceirização como técnica de gestão para se desvencilhar da responsabilidade e dos custos de contratação direta:

Do final dos anos 1990 para cá, nós estamos numa lógica de uma morte a cada 45 dias. Teve ano que ficou uma morte a cada 30 dias. Não tínhamos esta marca, com certeza foi a partir da terceirização que isso se agravou [...]. Eu me lembro que no começo da terceirização, a empresa concessionária sabia onde estava cada eletricista terceirizado e seu nome [...]. Hoje se perguntar à empresa ela não sabe quantas empreiteiras estão também fazendo o serviço, ela não se preocupa com o controle [...] (E1)

[...] o trabalho foi muito precarizado [...] e a responsabilização não chegou lá na empresa. Ela quantifica o custo do acidente, tem um cálculo para isso, mas, nem sempre é um custo da empresa, é um custo social, custo financeiro, mas social [...] do poder público [...] uma parte vai para empresa como perda de produtividade [...] pelo afastamento, mas somente quando é do quadro próprio. Quando é o terceiro, o departamento não conta, a responsabilidade é da outra empresa [...]. É uma pena [...]. (E2)

Na visão desses entrevistados, a situação é agravada pela dificuldade de incorporar os trabalhadores terceirizados na organização sindical:

\begin{abstract}
A terceirização afeta muito a organização sindical porque onde a gente vai achar o terceiro, ou ele está na rede ou está na empresa dele [...]. A gente tem muita dificuldade de contato com esse pessoal, [...] eles têm um certo receio de conversar com a gente, mas eles têm muita vontade de ter uma organização, a gente vê isso. Eles solicitam que a gente represente eles e a gente tem que reconhecer a nossa, fragilidade de atender todo esse povo porque a gente já tem dificuldade de atender todas as nossas empresas, [...] tem muito trabalho pra pouca gente [...] então o que normalmente a gente faz é entrar em contato com as pessoas acidentadas. É difícil também
\end{abstract}


porque a empresa se nega a dar o nome da pessoa, se nega a dizer onde foi $\mathrm{o}$ acidente etc. (E4).

A fragmentação da organização sindical e a classificação como construção civil de muitas empresas terceiras contratadas no setor elétrico refletem nas diferenças de contratação de eletricistas efetivos e terceirizados (Quadro 1).

Quadro 1: Resultados de Acordos Coletivos do Sindicato dos Eletricitários e de Acordos Coletivos do Sindicato da Construção Civil, em 2012.

\begin{tabular}{|c|c|}
\hline Categoria: Eletricitários & Categoria: Construção Civil \\
\hline Piso salarial: $\mathrm{R} \$ 1.355,94$ & Piso salarial: $\mathrm{R} \$ 990,00$ \\
\hline PLR : R\$ 4.265,68 & $\begin{array}{l}\text { PLR: } R \$ 844,12 \text {, com destinação de } 4 \% \text { ao } \\
\text { Sindicato }\end{array}$ \\
\hline $\begin{array}{l}\text { Avaliação PLR: não há descontos por } \\
\text { faltas decorrentes de afastamento por } \\
\text { acidentes de trabalho }\end{array}$ & $\begin{array}{l}\text { Avaliação PLR: há descontos por faltas } \\
\text { decorrentes de afastamento por acidentes } \\
\text { de trabalho }\end{array}$ \\
\hline Jornada de trabalho: 40 horas semanais & Jornada de trabalho: 44 horas semanais \\
\hline $\begin{array}{l}\text { Pagamento Adicional de Periculosidade } \\
\text {-até } 30 \% \text { do salário }\end{array}$ & Não há \\
\hline $\begin{array}{l}\text { Auxílio -refeição: } R \$ 500,00+ \\
\text { Auxílio - alimentação: } R \$ 155,41 \\
\end{array}$ & $\begin{array}{l}\text { Auxílio -refeição: } \mathrm{R} \$ 312,50 \\
\text { Auxílio- alimentação: Não há }\end{array}$ \\
\hline $\begin{array}{l}\text { Auxílio medicação para casos de } \\
\text { acidentes de trabalho }\end{array}$ & Não há \\
\hline $\begin{array}{l}\text { Clausulas de proteção para casos de } \\
\text { acidentes de trabalho }\end{array}$ & Não há \\
\hline \multirow[t]{2}{*}{$\begin{array}{l}\text { Clausulas de proteção para dispensa e } \\
\text { de políticas de emprego }\end{array}$} & Não há \\
\hline & Banco de horas ${ }^{* *}$ \\
\hline
\end{tabular}

Fonte: Adaptado de SILVA, 2015, p.94.

* Participação de Lucros e Resultados

** Utilizada como moeda de troca, intensificando a atividade diária pelo aumento da jornada de trabalho. Muitos trabalhadores terceirizados são originários de outras localidades e moram em alojamentos fornecidos pela empresa. 
A terceirização, ao estabelecer diferenças de vínculo de emprego e diferentes representações sindicais para a mesma categoria, tem como efeito a desigualdade de direitos para os trabalhadores, no tocante a salário, alimentação e proteção social nos acidentes de trabalho e dispensas coletivas.

Como outra face da mesma moeda, a jornada de trabalho maior, a introdução do sistema de banco de horas e a ausência de cláusulas de proteção para situações de infortúnio são indicativos de maior precarização do trabalho dos a terceirizados.

\section{A PERDA DE CONHECIMENTO E A DEGRADAÇÃO DO TREINAMENTO}

Outra importante questão destacada foi a desigualdade na formação e treinamento da força de trabalho:

Foi desativado o centro de treinamento que funcionava em prédio próprio e existia desde os anos 60. Era uma referência porque na época vinham trabalhadores de outros países [...] a privatização [...] acabou com essa capacitação" (E4).

Essa formação [...] de um eletricista era de 300 horas, quase 3 meses eles ficavam lá [no centro de treinamento], depois ele tinha que ter um acompanhamento de mais três meses por um profissional habilitado, ele não podia trabalhar sozinho, [...] só depois disto é que ele era considerado com habilidade. Agora, para os companheiros das terceirizadas, quando há treinamento é de 15 dias e esse trabalhador já é colocado na rede para trabalhar no sistema (E3).

A normativa vigente define que serviços em redes energizadas devem ser executados por eletricistas com treinamento específico e devidamente comprovado. No entanto, no trabalho real, os entrevistados apontam que a lógica da redução de custos fez com o tempo de treinamento diminuísse ou fosse negligenciado:

É um serviço muito precário, eles [os terceirizados] não têm esse treinamento que nós temos, eles não têm esse cuidado todo, [...] de constante avaliação técnica, de ter uma pessoa mais experiente para avaliar, eles não têm isso. Lá você vê muitos casos que vieram da construção civil e já estão subindo na rede ligada e correndo risco, sabe? É por isso que tem ocorrido muito acidente por esses lados" (E5). 
Na observação direta foi constatado que as equipes de linha viva foram reduzidas de cinco trabalhadores para formação em duplas, suprimindo os que davam suporte e cuidavam da logística do entorno da rua, com suas variabilidades previsíveis e imprevisíveis. Como o trabalho da linha viva é dinâmico e complexo, a decisão de redução do efetivo pode ensejar aumento da carga cognitiva dos eletricistas que trabalham em altura, com a linha energizada, exigindo-lhes, a um só tempo, atenção concentrada e difusa (as tarefas a serem executadas no poste e o entorno da rua), fragilizando estratégias de regulação habituais no lidar com o trânsito costumeiro de pedestres assim como interferências e questionamentos dos consumidores que se colocam ao pé do poste. Esses achados estão em consonância com a ideia de que com a redução do efetivo, a confiabilidade do sistema também foi reduzida (CASTRO, 2016).

\section{AÇÕES IMEDIATISTAS E A DEGRADAÇÃO DA MANUTENÇÃO}

Os entrevistados também fizeram outras críticas ao modelo de gestão das empresas privatizadas, que consideram centradas nos interesses rentistas dos acionistas e diminuição dos investimentos, levando a redução das práticas de manutenção preventiva:

[...] a rede nossa já está com tempo de vida útil comprometida e a proteção não está equilibrada, caso haja algum acidente tanto com trabalhador quanto com a população. Essa proteção não está equilibrada por falta de manutenção na rede (E6).

Para que eu vou investir em Segurança? [referindo-se ao pensamento dos gestores]. Eu vou cortar aquilo que não me dá retorno: Para que eu vou usar um alimentador até $90 \%$ da sua capacidade? Eu vou é usar até $130 \%$ ! Então, eu não vou fazer manutenção preventiva! (E6)

Na revisão tarifária, a ANEEL estabelece repasse de recursos para aumento de linhas de distribuição e transmissão relacionadas à ampliação do número de consumidores, como a instalação de um novo ramal de operações consideradas como investimento. As operações de 
manutenção, como trocas de cruzetas e postes antigos são consideradas como despesas antigas, tratadas como depreciação do capital, a cargo exclusivo das empresas ${ }^{24}$ :

A questão é o retorno. Se eu gastar mais com operação e manutenção eu vou estar considerando que seja fixa a depreciação. Depreciação é a reposição do meu capital. Eu estou fazendo uma disputa entre custo operacional e lucro, se eu gastar menos do que o regulador me passou na tarifa, o meu lucro vai estar sendo maior do que aquilo que foi dado na regulação. O contrário é verdadeiro, se eu estou gastando mais com operação e manutenção, eu estou comendo uma parte do lucro regulatório que foi dado. Quem faz a gestão do negócio vai estar fazendo todo o esforço para que a parte destinada ao lucro aumente e a manutenção preventiva significa gastar mais [...] (E7).

\section{A GESTÃO POR INDICADORES VERSUS A SEGURANÇA DO TRABALHO: OBJETIVOS CONTRADITÓRIOS}

As críticas dos entrevistados convergem nas formas de organização do trabalho mediadas por decisões gerenciais que predominaram no setor, e mostram os efeitos indiretos da metodologia de avaliação de eficiência utilizada pela agência governamental. No modelo regulatório da ANEEL a empresa que gastar menos é considerada mais eficiente, impactando positivamente em sua imagem e no desempenho de seus gestores:

[...] por incrível que pareça, esta metodologia que a ANEEL está usando, está forçando a terceirização nas empresas, principalmente nas empresas de distribuição. [...] ela usa a metodologia de comparação entre as empresas privilegiando aquelas que conseguem fazer o serviço a menor custo. Tanto é que a empresa que está no top, na avaliação da ANEEL, é a empresa que tem 95\% do seu quadro de terceirizados (E7).

E finalmente, as falas indicaram mais um elemento de estratégia gerencial de intensificação dos ritmos de trabalho, vinculado à terceirização - o pagamento por produção: O trabalhador recebe por produtividade, eles recebem o salário mínimo e tem que fazer produção por fora, que nem consta em carteira, para conseguir ter um ganho um pouco maior. Então esse trabalhador vai fazer uma produtividade maior de serviço, ele vai queimar etapas de segurança, que ele não conhece tão bem. Ele vai ganhar pelo número de ligações e de desligamentos que faz [...]. Isto não tem cabimento [...] daí vem os acidentes (E3). 
A política de avaliação de qualidade e preço da tarifa da agência reguladora está baseada em estimativas do tempo de interrupção do fornecimento de energia e na redução geral de custos, influenciando duplamente na decisão gerencial de ligar ou desligar a rede elétrica durante a execução dos serviços. O desligamento da rede reflete na diminuição do consumo de energia, interrompendo a medição e a cobrança. Os cortes de energia em menor frequência ou com menor tempo de duração, atendem as exigências dos indicadores FEC e DEC, garantindo boa avaliação de desempenho para as empresas e acréscimos de sua receita. O contrário significa perda financeira.

Desta forma, por um lado, são estimuladas autorizações de atividades em proximidade com redes primárias energizadas desprotegidas para evitar o desligamento, e por outro, há aceleração intencional do trabalho visando a redução do tempo de desligamento. Ambas as situações colocam os eletricistas em maior exposição aos riscos no manuseio de sistemas energizados.

As falas a seguir se referem a esta lógica gerencial que tem levado ao sucateamento das condições materiais de trabalho:

Um eletricista me relatou que na troca de uma cruzeta podre precisou ficar segurando a cruzeta com as duas mãos com os fios energizados, pois quando tiraram o parafuso, a cruzeta quebrou... Se não segurasse, ele e o parceiro iam levar o choque de 13,4kv [...] A vida útil da cruzeta é de 15 a 17 anos. "Temos aí cruzetas de 25, 30 anos que precisam ser trocadas, e quando for trocar não pode desligar a energia, a não ser que haja um investimento naquele local" (GF3).

[...] Depois do acidente a empresa foi lá e trocou 50 cruzetas que estavam em péssimo estado (GF4).

\section{ACIDENTE INCUBADO NA ORGANIZAÇÃO}

Estudo de caso de acidente grave do setor elétrico mostra em sua gênese vários fatores organizacionais (SILVA, 2015) e é apresentado de duas formas: a narrativa do "real do 
acidente", construída com base na fala do trabalhador e a narrativa técnica, construída com base no relatório da equipe de vigilância em saúde do trabalhador:

a) O real do acidente:

Era o nosso último atendimento do dia. Eram quase seis horas da tarde, a equipe tinha feito vários serviços e estava [...] exausta. Era um trabalho programado, uma substituição dos cabos elétricos de rede secundária em um condomínio fechado. Tinha um tempo de desligamento que foi falado aos moradores.

A linha primária foi mantida "viva" e passava muito perto das nossas cabeças quando a gente estava trabalhando no poste. A gente não sabia, mas tinha algumas árvores altas no caminho, o que atrasou muito o serviço. Tivemos que usar o [caminhão] munck, que, pela instrução de segurança só deveria ser usado quando a fixação do cabo no poste já tivesse terminado. Como a gente estava atrasado o Encarregado autorizou fazer junto.

O poste balançou, eu ouvi uma explosão e vi uma faísca elétrica. A linha arriou e se partiu. Eu tentei pular da escada, soltei um talabarte do cinto, mas fiquei pendurado pelo outro talabarte, apoiando nos fios de telefone. Eu levei o primeiro choque que entrou na minha perna esquerda e saiu por trás. Meu corpo parecia que ia estourar, parecia que estava enchendo. Tinha um fio de telefone embaixo e eu encostei na parte de trás do cabo, fazendo um aterramento, a energia passava por dentro de mim e ia para o chão.

Eu levei o primeiro choque e gritei - Desliga lá! Mas acho que ninguém me ouviu ou eu falei para mim mesmo, sei lá...

Deu então o segundo choque, eu pensei - pelo amor de Deus, eu quero ver meu filho pelo menos mais uma vez...

Deu o terceiro choque e eu desmaiei.

Na hora que eu acordei escutei o pessoal falando - morreu mais um companheiro nosso. Eu estava pendurado na escada pelo cinto, de capacete, de óculos, de calça antichama, mas quando olhei para baixo vi minha perna derretida. Tirei o equipamento, consegui descer e deitei no chão.

Aí chegou o SAMU e me levou para o hospital. Eu colocava minha mão atrás e sentia que escorria um líquido, uma água, parecia gordura, não sei. A perna tinha derretido, não morri por Deus, por um milagre. Se não fosse o fio do telefone eu tinha estourado, ia ficar levando choque até morrer!

A ANEEL adota um conjunto de indicadores de mensuração da qualidade de serviço e qualidade do produto, para garantir estes indicadores as concessionárias utilizam o religador automático, que tem a função de detectar uma condição anormal de sobrecorrente e interromper a distribuição da corrente elétrica, em seguida religa duas ou três vezes. $\mathrm{O}$ 
religador foi desenvolvido para corrigir falhas nas redes que tem origens diversas, incluindo queda e galhos de árvores, pássaros e ventos fortes, que interrompem a distribuição da energia elétrica em uma região. Portanto esta inovação tecnológica busca melhorar o desempenho da empresa diminuindo frequência e duração de interrupções do fornecimento de energia que são medidas pelos indicadores de avaliação da ANEEL. No caso do relato do acidente a série de choques sofrida pelo trabalhador é produto de escolhas organizacionais incubadas, um vez que os riscos de acidentes na rede elétrica aumentaram, porque a introdução desse sistema traz para o cenário da segurança a possibilidade de acidentes em que a vítima, que não participa das decisões de programação e/ou de ativação ou não do artefato, passa a conviver constantemente com problemas relacionados à programação, manutenção e confiabilidade dos dispositivos (SILVA et al., 2018).

Acresce que neste caso, as equipes de segurança da contratante e da contratada firmaram análise preliminar de perigos e riscos que definiu como sem risco de choque a atividade realizada cerca de 1,5 m abaixo de rede de alta tensão energizada. Mais grave só a decisão de deixar em operação religador que reenergizaria rede em que sabidamente havia terceiros trabalhando.

Embora a análise realizada não tenha encontrado colaboração que ajudasse a esclarecer quem e como tomou essas decisões - considerar sem risco elétrico a intervenção e manter em operação o religador naquela situação - foi possível reconhecer as duas como tendo papel crítico nas origens do evento e simultaneamente apontar dois núcleos atuação gerencial - na segurança e na programação de atividades - que atuaram resistindo ao completo esclarecimento dos processos de tomada de decisão no sistema. Tratam-se de escolhas ancoradas em práticas tais como historicamente adotadas na empresa e no sistema de regulação do setor elétrico brasileiro. Ou seja, de incubação do acidente em moldes que revelam como no cotidiano a empresa a lógica da produção prevalece sobre a da segurança no trabalho. Com o agravante da atuação subalterna na gestão de segurança de contratante e contratada que chegam ao extremo de participar ativamente em "avaliação preliminar de perigos e riscos". 
Há ainda falha crônica, incubada na gestão de primeiros socorros, em atividade em que o tipo de evento é previsível. A empresa opta por deixar o socorro para o setor público, o que implica tempo de espera muito maior, pois o setor de urgência e emergência tem outras demandas concomitantes, prolongando o tempo de atendimento, devido às distâncias de deslocamento e, muitas vezes, às dificuldades de acesso ao local do acidente. Quanto maior for o intervalo entre a ocorrência e o início dos primeiros cuidados, maior o risco de óbito ou de sequelas irreversíveis.

b) A retrospectiva técnica do acidente:

A equipe era de uma empresa contratada pela concessionária [...] para a manutenção em linhas secundárias e instalação de novas linhas. Apesar do trabalho ser realizado por eletricistas, tratava-se de uma atividade meio, considerada de construção civil, portanto, somente para atuar em sistemas desenergizados.

O serviço foi precedido de desligamento da linha secundária, entretanto, as linhas primárias energizadas estão situadas cerca de um metro acima, muito próximas umas das outras. Foi mantida a energização da linha primária com a finalidade de minimizar interrupções de fornecimento e impactos para os consumidores de um condomínio residencial.

O trabalhador atuava há um ano e meio em empresas terceirizadas do setor elétrico e tinha o curso de eletricista determinado pela legislação. Embora já houvesse realizado a mesma atividade em empregos anteriores, nesta empresa trabalhava há apenas 12 dias e pela primeira vez com a equipe. Foi colocado [...] em serviço sem passar por treinamento.

A cruzeta quebrada apresentava sinais evidentes de desgaste que diminuíram sua resistência. A existência de materiais em mau estado de conservação decorre de falhas de gestão da manutenção preventiva por parte da concessionária.

A religação automática consecutiva da energia após a queda da fiação, foi um fator agravante das lesões do trabalhador e seu não desligamento pela concessionária desconsiderou aspectos importantes da segurança ocupacional.

A instalação foi atrapalhada pela presença de árvores o que requereu o uso do caminhão munck, alterando o tempo planejado. A comunicação e a visibilidade entre os membros da equipe foram dificultadas pela presença das árvores e pela baixa iluminação na hora do acidente, por volta das $18 \mathrm{~h}$.

A empresa contratada realizou a Análise Preliminar de Perigos e Riscos (APPR), mas [...] não identificou previamente as variabilidades da atividade a presença de árvores entre postes e de cruzetas em mau estado de conservação. 
Outra falha na APPR foi não apontar a proximidade da linha primária energizada como perigo ou risco, não indicando que a mesma fosse isolada ou desligada. O não desligamento da energia atendia a interesses imediatos da contratante para agilização das tarefas.

Esses aspectos revelaram falhas na gestão de segurança da contratante e da contratada nas origens deste acidente e lacunas nas normas de segurança do setor.

A estratégia empresarial da concessionária ao usar a mão de obra de empresas terceiras em atividades de alto risco não fornece aos trabalhadores as mesmas condições dos trabalhadores próprios, como instruções, formações, instrumentos de trabalho. Por outro lado, a equipe terceira encontra-se em posição hierarquicamente inferior em relação à contratante, que não permite aos terceiros o poder de decisão de ligar ou desligar a energia da rede primária. A contribuição de relações sociais de poder nas origens de acidentes está em consonância com os achados da literatura (DWYER, 1991; GARRIGOU, 1999; DRUCK; FRANCO; BORGES, 2007; DANIELLOU et al., 2010 apud SILVA, 2015).

$\mathrm{O}$ acidente tem origem incubadas nas decisões estratégicas da concessionária, como autorizar intervenções próximas às linhas energizadas ou deixar a sua rede de energia por mais de 25 anos sem manutenção preventiva. Esta situação é agravada por adotar a terceirização que transfere atividades de exposição a riscos elétricos a empresas de construção civil sem requisitos de qualificação ou de experiência prática necessária ao trabalho. $\mathrm{O}$ uso repetido dessas práticas pode ter contribuído para a normalização ou banalização do risco que deve ser reconhecido como tal em análises preliminares conduzidas por profissionais especializados das empresas contratantes e contratadas.

A presença de árvores entre postes em que se dava a intervenção de equipe e que interferem tanto na visibilidade de membros do time entre si, como aumentando o grau de dificuldade na realização da tarefa de esticar a fiação por cima dessas árvores. Embora a presença das árvores pudesse ter sido registrada e considerada em análise preliminar de riscos, isso não aconteceu. Na prática, nem os tomadores de decisão que distribuíram a tarefa, nem a equipe que chegou a campo para intervir, consideraram que a situação encontrada na cena de trabalho mostrar-se-ia diferente do prescrito e que esta variabilidade não prevista 
pudesse afetar a segurança e merecesse mudanças, seja em cuidados adicionais de segurança, seja em habilidades e competências exigidas para a equipe de trabalho, seja em recursos disponibilizados (SILVA, 2015).

Outra falha incubada no sistema, de modo aparentemente paradoxal, é que as estruturas, ditas de gestão de segurança, de empresas concessionárias e terceiras adotam procedimentos formais de análise preliminar de perigos e riscos (APPR) que deixam de apontar, como perigos e riscos, problemas facilmente reconhecidos como a intervenção nas proximidades de linha primária energizada ou em área em que o dispositivo de religação está atuante. O agravante é que insistem na prática, mesmo depois de múltiplos acidentes agravados por tais situações. Desenvolvida nesse formato, a gestão se revela não só incapaz de defender o mero cumprimento de normas em atividade sabidamente de alto risco, ou seja, que claramente poderia se beneficiar da adoção das barreiras preconizadas na lei. Ela se situa à margem da evolução dos conhecimentos que destaca os limites da segurança prescrita e a necessidade de incorporação, em políticas e práticas de prevenção, da chamada segurança viva, por sua estreita relação com o reconhecimento da existência de variabilidades do trabalho e de suas implicações (SILVA, 2015).

\section{DIMENSÃO ORGANIZACIONAL}

As entrevistas reforçaram os achados deste estudo que ressaltaram o fato de que, no setor elétrico, a economia está comandada pela lógica financeira sustentada no curtíssimo prazo. Para Druck (2011) as empresas buscam garantir seus altos lucros, exigindo e transferindo aos trabalhadores a pressão pela maximização do tempo, pelas altas taxas de produtividade, pela redução dos custos com o trabalho e pela "volatilidade" nas formas de inserção e de contratos. Lima (2011 p. 163) aponta que a ascensão do capital financeiro na economia mundial tem sido acompanhada de formas agressivas e brutais de aumento da produtividade do trabalho por meio de modalidades de subcontratação e terceirização das atividades, com os objetivos de minimizar custos e amortecer os impactos de imprevistos da conjuntura econômica. 
Este caso destaca os efeitos desta precarização, em especial da degradação de condições de trabalho no setor elétrico brasileiro, cujas origens remontam há mais de vinte anos e parecem resultar em envelhecimento e sucateamento do sistema e indícios de intensificação de ritmos de trabalho nas origens desses eventos.

A terceirização é apontada como um dos fios condutores da precarização do trabalho no setor elétrico. Essa prática gerencial é, ao mesmo tempo, forma de contrato flexível e com menor proteção trabalhista e sinônimo de risco à saúde e à vida. Ela embutiria "manto de invisibilidade" posicionado sobre as condições sociais da classe trabalhadora agindo como facilitadora do descumprimento da legislação trabalhista (KREIN, 2009).

O enfraquecimento de coletivos de trabalhadores, com a consequente diluição e desvalorização das experiências e saber prático, surgem das narrativas dos diretores sindicais, bem como emergem dos casos analisados. O modelo de gestão pela terceirização está fragmentando a categoria sindical e, com isto, fragilizando as ações das entidades coletivas. A terceirização é instrumento de incremento da pulverização estrutural da organização sindical brasileira, incentivando a concorrência entre trabalhadores, entre eles e sindicatos e entre sindicatos, intensificando a alienação e a desvalorização humana do trabalhador (FRANCO, et al, 2010; ANTUNES \& DRUCK, 2013, p. 224).

Este estudo em consonância com o estudo do Dieese (2010) aporta evidências em favor do reconhecimento de que as formas atuais de incentivo à terceirização no setor elétrico brasileiro estão nas origens da piora de seus indicadores de saúde e segurança, em particular via introdução de iniciativas que fragilizam o alcance de medidas de prevenção contra os riscos da eletricidade consagrados na legislação do país, com destaque para o incentivo a permissões de trabalho nas proximidades de "linhas vivas", mas também pela abertura do trabalho a empresa do ramo da "construção civil" que, neste caso, se mostra incapaz de aplicar adequadamente as medidas de segurança preconizadas para o setor elétrico. Os possíveis limites a serem apontados neste estudo estão em não se ter demonstrado as entranhas dos processos de tomados de decisão, que a análise mostrou como associado à origem do acidente. Em outras palavras, quem, em que circunstâncias, com que objetivos, por quais razões decidiu-se interromper ou precarizar práticas de manutenção? Como a empresa 
autoriza intervenções abaixo de redes primárias energizadas e desprotegidas, desconsiderando a existência de risco grave e iminente de morte por choque elétrico?

O mesmo limite surge em relação ao esclarecimento das origens de processo de terceirização que repassa atividades historicamente realizadas no setor elétrico a empresas de construção civil. Quem e como escolheu regulação que permite a transferência desse tipo de atividades para empresas de construção civil. Como o papel das competências requeridas por trabalhadores experientes do setor elétrico nessas tarefas foi ou deixou de ser considerado na nova regulação? Como os gestores da contratante valorizaram essa questão no desenho dos contratos de terceiras após aprovação das novas regras?

Esclarecer os meandros desses processos exigiria acesso aos participantes dos níveis hierárquicos de gestão de diferentes áreas estratégicas da empresa e sua disposição para colaborar com informações que "a priori" são vistas como possíveis ameaças jurídicas às empresas. O impasse se dá em torno da disputa por acesso a informações em questões que as empresas tradicionalmente nunca aceitaram que se dessem como produtos de negociações democráticas. Pelo contrário, sempre consideraram de sua competência decidir como gerenciar, não aceitando como interlocutores válidos representantes de serviço de saúde que historicamente não intervinham nessas questões. Ao apontar tais limites, este estudo passa a apresentar como um de seus pontos fortes aquilo que inicialmente poderia aparecer como fraqueza. Se quisermos avançar na institucionalização de práticas de análise e prevenção de acidentes é preciso empoderar os atores que nela atuam, de modo a ampliar seu acesso às informações sobre decisões estratégicas da gestão da empresa, as quais se mostram associadas às origens de acidentes.

\section{REPERCUSSÕES ADVERSAS PARA O TRABALHADOR ACIDENTADO}

$\mathrm{Na}$ ocasião da pesquisa, o trabalhador amputado por choque elétrico estava em adaptação de prótese mecânica, comprada pela empresa, em município distante 150 km de sua moradia. O processo de confecção e adaptação de marcha requeria várias idas e vindas à ortopedia do município da compra, impondo dificuldades físicas de locomoção, bem como, 
em despesas de transporte e pedágios. A ajuda da empresa foi insuficiente para cobrir a totalidade destes gastos, bem como da regularização da Carteira Nacional de Habilitação $\mathrm{CNH}$ para o uso da prótese. Os relatos do trabalhador revelaram descaso, por parte da empresa, em relação às suas dificuldades.

O trabalhador expressou ainda outras perdas, destacando sentimentos de sofrimento pela incapacidade de realizar suas atividades de "skatista", esporte que praticava desde menino, tinha patrocínio e já havia participado, com destaque, de vários campeonatos. O lazer também foi comprometido pois não se sentia mais capaz de jogar futebol com os amigos e passear de motocicleta.

No setor de distribuição de energia elétrica, o trabalho tem reconhecida periculosidade porque seus trabalhadores lidam com a passagem de correntes elétricas de altas voltagens. Nas linhas de distribuição aos consumidores, as linhas secundárias, em baixa tensão, podem variar de 110,127, 220, 380 e 440 volts, e, as linhas primárias, em alta tensão, têm variação de 11.000 a 13.800 volts.

Segundo Amalberti (2016), em grandes sistemas sócio técnicos, como os energéticos, o desafio à gestão de segurança e de confiabilidade é maior porque a exposição ao perigo é assumida como socialmente aceitável. Assim, o objeto da segurança consiste em encontrar soluções para evitar, não o risco, e sim os acidentes.

Trabalhar sem acidentes e sem falhas exige, além da técnica, a gestão de outras dimensões associadas ao risco, como por exemplo, de aspectos econômicos, políticos ou sociais. Em outras palavras, a segurança no trabalho real envolve a construção de compromisso baseado na negociação de interesses em suas várias dimensões. $\mathrm{O}$ trabalhador precisa trabalhar com segurança, respeitando prazos e entregando serviço bem feito independentemente de constrangimentos temporais, atrasos, adequação ou inadequação de meios disponibilizados, da capacitação da força de trabalho designada (AMALBERTI, 2016).

No caso estudado, o compromisso assumido embutia fragilidades de origem como o fato da análise preliminar de perigos e riscos não considerar como exposição a risco elétrico a intervenção em rede secundária desenergizada, situada apenas a um metro de distância de rede primária energizada. 
Do mesmo modo, existiu uma contribuição do religador automático na linha de transmissão. No acidente em questão, o sistema continuou ligado, provavelmente porque seu desligamento foi programado para nível de sobrecarga elétrica superior à ocorrida. Ao ser religado três vezes, causou novos e sucessivos choques elétricos ao trabalhador, agravando as lesões, resultando em amputação da perna esquerda do trabalhador. A lógica da inovação, voltada para a produtividade e garantia de abastecimento, embutia riscos não previstos (SILVA et al., 2018).

Nas origens das decisões é possível encontrar aspectos do contexto macropolítico que Amalberti (2016) relacionou como associados a acidentes, pois, o gestor se vê colocado em meio a disputa de interesses da segurança dos trabalhadores e os de produtividade e qualidade a custo baixo, esperados pelo modelo de avaliação de desempenho adotado pela ANEEL.

\section{CONCLUSÃO}

Este estudo de caso é emblemático da necessidade de abordagens que considerem a integralidade dos efeitos adversos dos acidentes de trabalho. A análise conduzida adota modelo de gravata-borboleta como forma de pensar o acidente (HALE et al, 2007), destacando a necessidade de explorar o chamado lado direito da gravata, ou seja, para além do desfecho imediato, como o choque e as queimaduras em membro inferior, enfatizando as consequências tardias na vida do trabalhador - físicas e psíquicas - com impactos nas suas relações pessoais, no seu papel social na família, acesso a direitos sociais e assistência, etc.

A ANEEL contribui de modo determinante na esfera macropolítica uma vez que modela e induz processos de tomada de decisões de concessionárias de energia elétrica. Com a privatização das empresas estatais de distribuição de energia elétrica constituiu-se mercado de compra e venda de energia cujo funcionamento procura estimular práticas de livre concorrência.

O papel da ANEEL é o de regulamentar as bases para a livre concorrência econômica e racionalização dessa atividade (ROSA, 2008). Para tanto, instituiu indicadores de qualidade do 
fornecimento de energia elétrica FEC e DEC, agora associados a um modelo de avaliação de desempenho para repasse de reajustes tarifários, com a finalidade de reduzir custos operacionais e aumentar a eficiência e qualidade do serviço.

Por meio do Indicador de Desempenho Global de Continuidade, a ANEEL premia empresas que apresentem menores custos e que diminuem o tempo de corte de energia aos consumidores. Para diminuir os custos, as empresas são estimuladas, por um lado, a diminuir o tempo de interrupção do fornecimento e, por outro, a reduzir gastos com pessoal e diminuir os investimentos em manutenção.

Apesar dos possíveis limites apontados neste estudo, as decisões gerenciais advindas deste modelo concorrencial - aumento da terceirização para redução de gastos, intensificação do trabalho para diminuição do tempo de interrupção de energia, bem como, redução dos investimentos em manutenção, sucateamento da rede elétrica e precarização generalizada do trabalho - trazem o aumento da exposição ao risco de choque elétrico. As origens do acidente se associam a decisões adotadas pela gestão pela obtenção de melhores resultados nos indicadores de custo e qualidade da ANEEL. A desumanidade desse modelo pode ser ainda maior se os acidentes forem considerados como mera externalidade do caminho escolhido para gestão da privatização no setor elétrico brasileiro.

A gravidade das lesões e as incapacidades decorrentes dos acidentes por choques elétricos, estabelecem custos intangíveis aos trabalhadores acidentados, tais como dificuldades de reintegração familiar, no meio social onde vivem e nas relações de trabalho com as empresas. De complexa medição de seus impactos a vida humana, são considerados intangíveis porque não podem ser quantificados em moeda corrente, mas podem ser percebidos em seu conteúdo destrutivo quando retratado em casos reais (TAKAHASHI E CERVENY, 2016).

Acredita-se que o verso e o anverso (MENDES, 2003) do acidente, mutilador da "luta pela vida" de um jovem trabalhador, dá visibilidade e concretude às consequências reais de um ideário economicista financeiro hegemônico, que tem sido acompanhado de formas agressivas de aumento da produtividade, às custas de morte e adoecimento dos trabalhadores. 


\section{REFERÊNCIAS BIBLIOGRÁFICAS}

AMALBERTI, R. Gestão da segurança: teorias e práticas sobre as decisões e soluções de compromisso necessárias. Botucatu: FMB -UNESP; 2016.

ANEEL - Agência Nacional de Energia Elétrica. Nota Técnica no 265/2010-SRE. Metodologia de cálculo de custos operacionais. Brasília: ANEEL; 2010.

ANEEL - Agência Nacional de Energia Elétrica. Nota Técnica no 60/2018-SGT. Quarta revisão tarifária periódica. Brasília: ANEEL; 2018.

ANTUNES, R. A corrosão do trabalho e a precarização estrutural. Revista Margem Esquerda. v. 18, p. 42-47, 2012.

ANTUNES, R.; DRUCK, G. A terceirização como regra? In: Rev. TST, v. 79, n. 4, 2013.

BALL, S.J. Performatividade, privatização e o pós-Estado do Bem-Estar. Educ. soc. v. 25, n. 89, p. 1105-1126, 2004.

BINDER, M. C. P.; MONTEAU, M.; ALMEIDA, I. M., Árvore de Causas. Método de Investigação de Acidentes do Trabalho. São Paulo: Publisher Brasil Editora, 1995.

BRASIL. Ministério de Trabalho e Previdência Social. Portaria no 508, de 29 de abril de 2016. Altera a Norma Regulamentadora NR - 10 - Segurança em instalações e serviços em eletricidade. Brasília, Diário Oficial da União, 2 mai. 2016.

CASTRO V.C., OLIVEIRA M.A. Corta circuito religador temporizador. 2001. Disponível em: <http://www.aneel.gov.br/biblioteca/Citenel2001/trabalhos/34.pdf>. Acesso em: 29 out. 2019.

CASTRO, M.G.L. Quando as luzes se apagam... a gestão coletiva dos riscos na manutenção em rede energizada. Dissertação (Mestrado em Engenharia de Produção) - Universidade Federal de Minas Gerais, Belo Horizonte, 2016.

DiEESE - Departamento Intersindical de Estatística e Estudos Socioeconômicos. Terceirização e morte no trabalho: um olhar sobre o setor elétrico brasileiro. Estudos e pesquisas. São Paulo: DiEESE; 2010. 
DiEESE - Departamento Intersindical de Estatística e Estudos Socioeconômicos. Nota técnica no 134. As tarifas de energia elétrica no Brasil: inventário do 3 ciclo de revisão tarifária e os efeitos sobre o setor. São Paulo: DiEESE; 2014.

DiEESE - Departamento Intersindical de Estatística e Estudos Socioeconômicos. Nota técnica no 172. Terceirização e precarização das condições de trabalho. Condições de trabalho e remuneração em atividades tipicamente terceirizadas e contratantes. São Paulo: DiEESE; 2017.

DRUCK, M.; FRANCO, T.; BORGES, A. A perda da razão social do trabalho: terceirização e precarização. Campinas: Boitempo Editorial; 2007.

DRUCK, G. Trabalho, precarização e resistências: novos e velhos desafios? Caderno CRH, v. 24, n. spe 1, p. 37-57, 2011.

DRUCK, G. A terceirização na saúde pública: formas diversas de precarização do trabalho. In: Trab. educ. saúde (online). v.14, n.1. p.15-43, 2016.

FRANCO, T.; DRUCK, G.; SELIGMANN-SILVA, E. New labor relations, worker's mental exhaustion, and mental disorders in precarious work. Rev. Bras. Saúde Ocup., v. 35, n. 122, p. 229-248, 2010.

GUÉRIN F, LAVILLE A, DANIELLOU F, DURAFFOURG J, KERGUELEN A. Compreender o trabalho para transformá-lo: a prática da Ergonomia. São Paulo: Edgard Blücher Ltda.; 2004.

KREIN, J.D. Tendências recentes nas relações de trabalho no Brasil. In: BALTAR, P.E.A.; KREIN, J.D.; SALAS, C. Organizadores. Economia e trabalho: Brasil e México. 7. 1 ed. São Paulo: CESIT, UNICAMP, IE-Instituto de Economia; 2009. p. 199-226.

HALE, A.R. et al. Modeling accidents for prioritizing prevention. Reliab. Eng. Syst. Safety. v. 92, n. 12, p. 701-1715, 2007.

HOLLNAGEL, E. Barriers and accident prevention. Aldershor: Ashgate, 2004.

HOLLNAGEL, E. Risk + barriers = safety? Safety Sci, n. 46, p. 221-229, 2008.

LE COZE, J-C. 1984-2014. Normal Accidents. Was Charles Perrow right for the wrong reasons? JCCM. v. 23, n. 4, p. 275-286, 2015.

LIMA, M. E. A. Trabalho e saúde mental no contexto contemporâneo de trabalho: possibilidades e limites de ação. In: ALVES, G.; VIZZACARO-AMARAL, A. L.; M. D. P. (Org.) 
Trabalho e Saúde: A precarização do trabalho e da saúde do trabalhador no século XXI. São Paulo: LTr, 2011 p.161-172.

LLORY, M. Acidentes industriais: o custo do silencio. Rio de Janeiro: Multimais;1999

LLORY, M.; MONTMAYEUL, R. $O$ acidente e a organização. Belo Horizonte: Fabrefactum, 2014.

MAIA, B.; MACHADO, C. Dublê de eletricista. Um documentário sobre a terceirização no setor elétrico brasileiro [documentário]. Brasil: Sindieletro MG; 2015. 20 min.

MANDARINI, M.B.; ALVES, A.M.; STICCA, M.G. Terceirização e impactos para a saúde e trabalho: uma revisão sistemática da literatura. rPOT. v. 16, n. 2, p. 143-152, 2016.

MENDES, J.M.R. $\mathbf{O}$ verso e o anverso de uma história: $\mathbf{o}$ acidente e a morte no trabalho. Porto Alegre: EDIPUCRS; 2003.

MILCH, V.; LAUMANN, K. Interorganizational complexity and organizational accident risk: a literature review. Safety sci. v. 82, p. 9-17, 2016.

NOVAES, J.R.; SILVA, A.J.N. Eletricitários [documentário]. Brasil: Prodprevenir; 2016. 21 min.

PAIM, J. A reforma sanitária e os modelos assistenciais. In: ROUQUAYROL, M.; ALMEIDAFILHO, N. Organizadores. Epidemiologia e Serviços de Saúde. Rio de Janeiro: Medsi; 1999. p. 473-487.

PERROW, C. Normal accident. Living with high risk technologies. Princenton: Princenton University Press, 1999

POUPART, J. et al. A pesquisa qualitativa: enfoques epistemológicos e metodológicos. 3 ed. Petrópolis: Vozes; 2012.

REASON, J. Managing the risks of organizational accidents. Aldershot: Ashgate, 1997.

ROSA, Á.D. Agências reguladoras e estado no Brasil: reformas e reestruturação neoliberal nos anos 90. 2008. Dissertação (Mestrado em Ciências Sociais) - Faculdade de Filosofia e Ciências, Universidade Estadual Paulista, Marília, 2008.

GOMES DA SILVA, L.G.G. Os acidentes fatais entre os trabalhadores contratados e subcontratados do setor elétrico brasileiro. Estudos de trabalho. v. 6, n.12, 2013. 
SILVA, A.J.N. Análise organizacional de acidentes de trabalho no setor de distribuição de energia elétrica. 2015. Dissertação (Mestrado em Saúde Coletiva) - Faculdade de Medicina, Universidade Estadual Paulista “Júlio de Mesquita Filho", Botucatu, 2015.

SILVA, A.J.N. et al. Acidentes de trabalho e os religadores automáticos no setor elétrico: para além das causas imediatas. Cad. Saúde Pública. v. 34, n. 5, 2018:e00007517.

TAKAHASHI, M.A.B.C.; CERVENY, G.C. Impacto Social dos acidentes de trabalho no município de Piracicaba: intervenção e busca compartilhada pela integralidade em saúde. In: ASENSI F, PINHEIRO R, MUTIZ PA, organizadores. Bioética, Trabalho e Educação em Saúde. Rio de Janeiro: Multifoco; 2016. p. 67-77.

WEIDENBAUM, M. Outsourcing: Pros and cons. Business Horizons. v. 48, n.4 p. p. 311-315, 2005. 